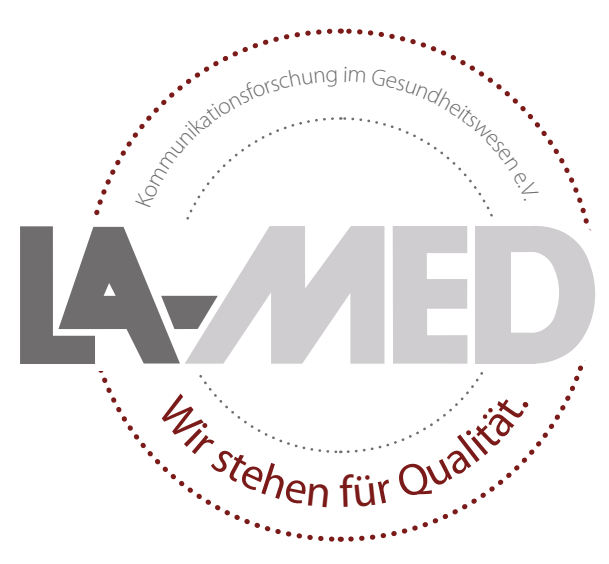

\section{Sie lesen Qualität}

Damit das auch so bleibt, befragen wir Sie in Kooperation mit $\operatorname{tn} \mathbf{s}$ infratest in den nächsten Wochen.

Ihr Urteil ist uns wichtig. Bitte nehmen Sie teil!

\title{
Völlig gehunfähig, aber ganz flott auf dem Fahrrad
}

Ein 58-jähriger Mann litt seit zehn Jahren unter einem Morbus Parkinson und wurde wegen völliger Gehunfähigkeit in eine neurologische Klinik überwiesen. Gehversuche führten bereits nach wenigen Schritten dazu, dass der Mann vornüberfiel und auf den Boden stürzte.

- Wenn die Physiotherapeutin ihren Fuß als visuelles Muster vor dem Patienten aufsetzte, so war dieser in der Lage, einige wenige Schritte zu gehen.

Bei der Untersuchung erwähnte der Patient beiläufig, dass er noch wenige Tage zuvor 15-25 km mit dem Fahrrad geradelt sei. Der Untersucher wollte das nicht glauben, der Patient erklärte sich aber bereit, seine Fähigkeiten sofort auf dem Parkplatz vor dem Krankenhaus zu demonstrieren. Eine Krankenschwester stellte ihr Fahrrad zur Verfügung, man schob den Patienten leicht an und er drehte eine elegante Runde auf dem Parkplatz und kehrte sicher zum Ausgangspunkt zurück. Nach dem Absteigen vom Fahrrad stellte sich die vollständige Gehunfähigkeit sofort wieder ein.

Offensichtlich handelt es sich bei diesem erstaunlichen Phänomen nicht um einen Einzelfall. Der behandelnde Neurologe befragte spontan 20 seiner Parkinsonpatienten mit schwerer Gangstörung, und mehrere berichteten, dass sie beim Fahrradfahren keine Probleme hätten. Offensichtlich ist dieses hochinteressante Phänomen der Aufmerksamkeit sämtlicher Neurologen bisher entgangen.

\section{Kommentar}

Über die Mechanismen kann man nur spekulieren. Möglicherweise wirkt die rotierende Bewegung und der durch die Pedale vorgebahnte Aktionsradius als Schrittmacher für die Initiierung der Bewegung und setzt motorische Kontrollmechanismen in Gang, die beim Gehen nicht wirksam sind. Radfahren ist möglicherweise ein neuer therapeutischer Ansatz für das Bewegungstraining von Parkinsonpatienten, die aufgrund ihres eingefrorenen Gangs zur Bewegungsunfähigkeit verurteilt sind. Die Geschichte erinnert etwas an den berühmten Fall eines Parkinsonpatienten in einem Pflegeheim, der völlig gehunfähig war, der aber bei einem Brand in dem Pflegeheim ohne Probleme die Treppe benutzen konnte. Als er im Freien angelangt war, stellte sich die Gehunfähigkeit wieder ein. Eindrucksvolle Beispiele, wie bei äußeren Reizen, die wir längst nicht kennen, die Funktion geschädigter Hirnareale durch andere Anteile übernommen werden kann. Vom Patienten lernen!

H. S. FÜEßL =

\section{- A. H. Snijders, B. R. Bloem}

(Donders Institute for Brain, Cognition and Behavior, Radboud University Nijmegen Medical Center, Nijmegen, The Netherlands): Cycling for freezing of gait. New Engl. J. Med. 362 (2010) 13, e46
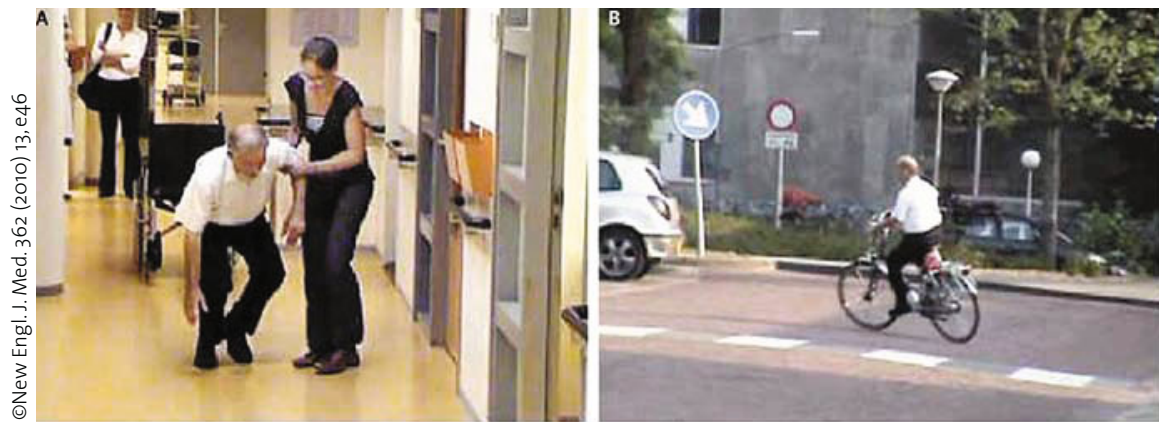

Der Patient kann nur wenige Schritte gehen, hat aber keine Probleme beim Radfahren. 